\title{
An Experimental Study of the Effect of Thermal Treatments \& Charpy Impact Test Parameters on Impact Toughness of EN31 Steel
}

\author{
Khangamlung Kamei ${ }^{1}$, Anna Garima William ${ }^{1}$, L.S Koveile ${ }^{1}$, Noman Ahmad ${ }^{1}$, \\ Ananyo Chakravorty ${ }^{1}$, Rahul Davis ${ }^{2}$ \\ ${ }^{\prime}$ B.Tech Student, Department of Mechanical Engineering, Shepherd School of Engineering and Technology, \\ Allahabad, Uttar Pradesh, India \\ ${ }^{2}$ Assistant Professor, Department of Mechanical Engineering, Shepherd School of Engineering and Technology, \\ SHIATS, Allahabad, Uttar Pradesh, India
}

\begin{abstract}
Engineering materials, mostly steel and their alloys are heat treated to alter their mechanical and physical properties so as to meet the engineering applications. The objective of the research was to maximize the impact toughness by selecting various combinations of Charpy Impact test parameters, thermal treatments and their appropriate levels based on the three-level (L9) Orthogonal Arrays (OAs) with four factors to provide an efficient and effective method for determining the most significant factors and interactions in the given design problem. In this paper experiments were carried out to Study the Effect of Thermal Treatments (annealing, hardening, cryogenic treatment and tempering) on Impact Toughness. Heat treatments were performed at different temperature for annealing, hardening and tempering in an Electric furnace. Deep cryogenic treatment (DCT) was carried out on Cryocan at $77 \mathrm{~K}$. Various combinations of heat treatment cycles were performed to improve the mechanical properties of EN31 steel. This experimental also investigated the role of multiple cryogenic treatments before and after tempering. The findings show that Cryogenic treatment improves hardness, dimensional stability, and retained austenite to martensite and decreases residual stresses. This paper also studied and measured the hardness of various heat treated specimens using Brinell Hardness tester.
\end{abstract}

Keywords: EN31 Steel, Impact Toughness, Orthogonal Arrays (OAs), Thermal Treatments, Cryogenic Treatment

\section{Introduction}

During World War II, a US cargo vessels 'Liberty Ship' were reported to damage due to brittle fracture. These mark the Start of the discipline of fracture mechanics [1]. Since then, many engineers and researchers had studied about this fracture. In 1978, AASHTO introduced a fracture control plan [2] in the aftermath of the Silver Bridge collapse in 1967 due to brittle fracture .The finding of all these researches concluded that these fractures was due to lack of understanding of the ductile-to-brittle transition $[1,3]$.

Recently many industries and researchers were interested in cryogenic treatment. Cryogenic treatment is an extension of conventional heat treatment (CHT) which converts retained austenite to martensite.[4] Lipson(1967) studied the effect of cryogenic treatment on the grain size and suggested that the cryogenic treatment reduces grain size by $1-4 \%$. This refinement of grain structure would increase in toughness of the specimens.

Cryogenic treated materials enhanced the mechanical properties. CT brings about thermal instability to martensite by means of supersaturating it with carbon which further leads to migration of carbon atoms and atoms of alloying elements to the nearby lattice defects and segregate there [5]. Cryogenic treatment improves not only toughness but also microstructure of mental and decrease residual stresses.

\section{Heat Treatment Sequence for Maximizing Martensite Transformations}

The complete treatment process of the steels consists of hardening that is austenitizing and quenching, cryo-treatment or deep cryogenic treatment (DCT), and Tempering. To achieve better microstructure of the steel and to get most desired properties, it is recommended by the most researchers to execute DCT after completion of quenching and before tempering in conventional heat-treatment cycle as shown in Fig-1. The complete process sequentially consists of Austenitizing, quenching, cryo-processing and tempering.

Conventional heat treatment consists of annealing, hardening and tempering, while deep cryogenic treatment involves an additional low temperature treatment cycle to conventional heat treatment process. Arockia Jaswin et.al [6] determined that the cooling rate for EN 52 and $21-4 \mathrm{~N}$ valve are respectively $1{ }^{\circ} \mathrm{C} / \mathrm{min}$ and $1.5^{\circ} \mathrm{C} / \mathrm{min}$. A. Joseph Vimal et.al [7] state Cryogenic treatment refers to sub-zero temperature of EN31 
steel to $90 \mathrm{~K}$ in 3 hours and soaking time at that temperature for 24 hours and allowing it to attain room temperature in another 6 hours. The various heat treatment cycles is indicated in fig. 1 below:

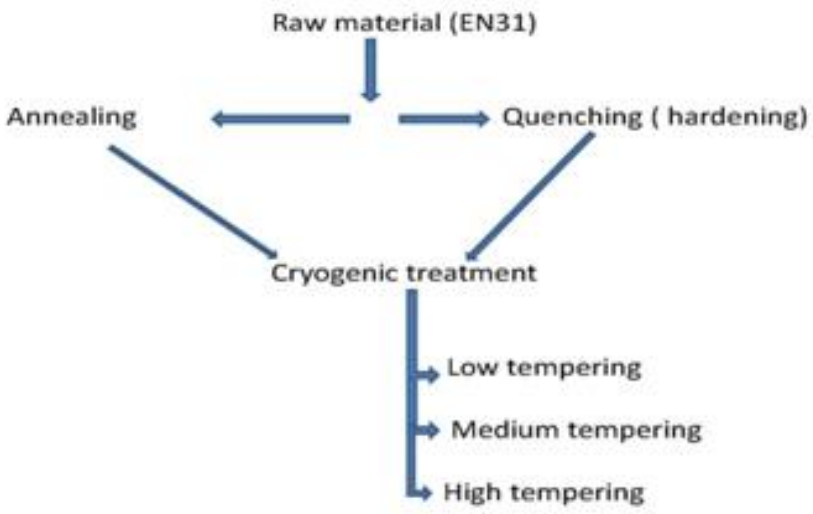

Fig: 1: Thermal Treatments

\subsection{Design of Experiment (DOE)}

III. Materials and Methods

It is methodology based on statistics [8] and other discipline for arriving at an efficient and effective planning of experiments with a view to obtain valid conclusion from the analysis of experimental data [9]. The design of experiment (DOE) is done in such a way to find a parameter that will improve the performance characteristic to an acceptable or optimum value. It is also kept in mind that the design will enable us to find a less expensive, alternative design, material, or methods which will provide equivalent performance. Depending on which situation the experiment are carried out, different strategies are use.

The experiment carried out is based on the principle of Orthogonal Arrays (OAs). This principle [10] state that factors can be evaluated independently of one another; the effect of one factor does not bother the estimation of the effect of another factor. DOE is a balanced experiment: an equal numbers of samples under the various treatment conditions.

The control parameters were considered for the proposed research work for multiple performance characteristics at three different levels and four different factors and are shown in Table 1 below:

Table 1: Different Factors and their Levels for Annealing EN 31

\begin{tabular}{|cccc|}
\hline Factors & Level 1 & Level 2 & Level 3 \\
\hline Notch Angle (A) & $30^{\circ}$ & $45^{\circ}$ & $60^{\circ}$ \\
\hline Thermal Treatment (B) & Annealing followed by & Annealing followed by & Annealing followed by Cryogenic \\
& Cryogenic Treatment \& Low & Cryogenic Treatment \& & Treatment \& High Temperature \\
& Temperature Tempering & Memperium Temperature \\
& (ACTLTT) & Tempering (ACTMTT) & $($ ACTHTT) \\
\hline Height of the Hammer $(\mathbf{C})$ & $1370 \mathrm{~mm}$ & $1570 \mathrm{~mm}$ & $1755 \mathrm{~mm}$ \\
\hline Temperature $(\mathbf{D})$ & $-196^{\circ} \mathrm{C}$ & $-50^{\circ} \mathrm{C}$ & $28^{\circ} \mathrm{C}$ \\
\hline
\end{tabular}

In this paper the effect of thermal treatments was studied along with four impact test parameters to maximize the impact toughness of EN31 steel. The experiment is to find the optimum impact value by combining all parameters like notch angle, thermal treatment, height of hammer at different temperature condition.

The material chosen in this work was given various thermal treatments. Specimens were subjected to conventional heat treatment and deep cryogenic treatment separately.

Table 2.Different Heat Treatments Employed to EN 31 steel

\begin{tabular}{|c|c|c|}
\hline Sr. No. & Nomenclature & Thermal Treatment \\
\hline 1 & ACTLTT & $\begin{array}{l}\text { Annealing }\left(810^{\circ} \mathrm{C} \text { for } 1 \mathrm{hr}\right) \text { followed by Cryogenic Treatment \& Low Temperature Tempering } \\
\left(250^{\circ} \mathrm{C} \text { for } 1 \mathrm{hr}\right)\end{array}$ \\
\hline 2 & ACTMTT & $\begin{array}{l}\text { Annealing }\left(810^{\circ} \mathrm{C} \text { for } 1 \mathrm{hr}\right) \text { followed by Cryogenic Treatment \& Medium Temperature Tempering } \\
\left(400^{\circ} \mathrm{C} \text { for } 1 \mathrm{hr}\right)\end{array}$ \\
\hline 3 & ACTHTT & $\begin{array}{l}\text { Annealing }\left(810^{\circ} \mathrm{C} \text { for } 1 \mathrm{hr}\right) \text { followed by Cryogenic Treatment \& High Temperature Tempering } \\
\left(550^{\circ} \mathrm{C} \text { for } 1 \mathrm{hr}\right)\end{array}$ \\
\hline
\end{tabular}

\subsection{Chemical compositions}


An Experimental Study of the Effect of Thermal Treatments and Charpy Impact Test Parameters...

The Chemical composition test of EN 31 steel was performed in the Metal Testing Laboratory, Indian Railways in Bareilly (U.P.), India. The details of composition are shown below:

Table 3: Chemical Composition of EN31 Steel

\begin{tabular}{|ccc|}
\hline Sl. No & Composition & Percentage \\
\hline $\mathbf{1}$ & $\mathrm{C} \%$ & 1.10 \\
\hline $\mathbf{2}$ & $\mathrm{Mn} \%$ & 0.46 \\
\hline $\mathbf{3}$ & $\mathrm{Si} \%$ & 0.22 \\
\hline $\mathbf{4}$ & $\mathrm{Cr} \%$ & 1.08 \\
\hline $\mathbf{5}$ & $\mathrm{S} \%$ & 0.023 \\
\hline $\mathbf{6}$ & $\mathrm{P} \%$ & 0.026 \\
\hline
\end{tabular}

Design of experiment is an effective tool to design and conduct the experiments with minimum resources. Orthogonal Array is a statistical method of defining parameters that converts test areas into factors and levels. Test design using orthogonal array creates an efficient and concise test suite with fewer test cases without compromising test coverage. In this paper, L9 Standard Orthogonal Array design matrix was used to set the control parameters to evaluate the process performance. Table 4 shows the design matrix used in this work.

\subsection{Charpy Impact test}

The Charpy impact test, also known as the Charpy V-notch test, is a destructive testing method which determines the amount of energy absorbed by a material during fracture. This absorbed energy is a measure of a given material's notch toughness and acts as a tool to study temperature-dependent ductile-brittle transition. Charpy impact test is practical for the assessment of brittle fracture of metals and is also used as an indicator to determine suitable service temperatures. The Charpy test sample has a sizes $(10 \mathrm{X} 10 \mathrm{X} 55) \mathrm{mm}^{3}$ with three VNotch $30^{\circ}, 45^{\circ}$ and $60^{\circ}$ of $2 \mathrm{~mm}$ depth will be hit by a pendulum at the opposite end of the notch

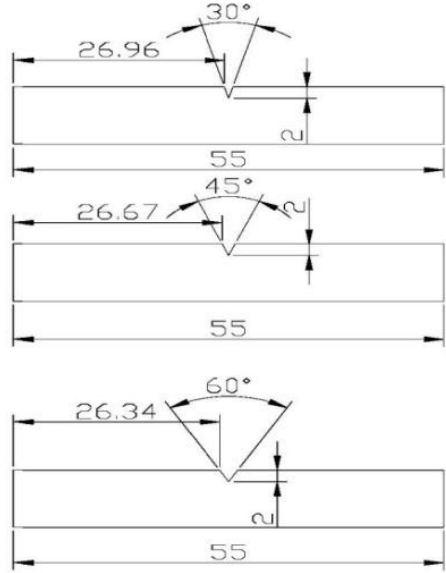

Fig: 2 Dimension of Test Specimen

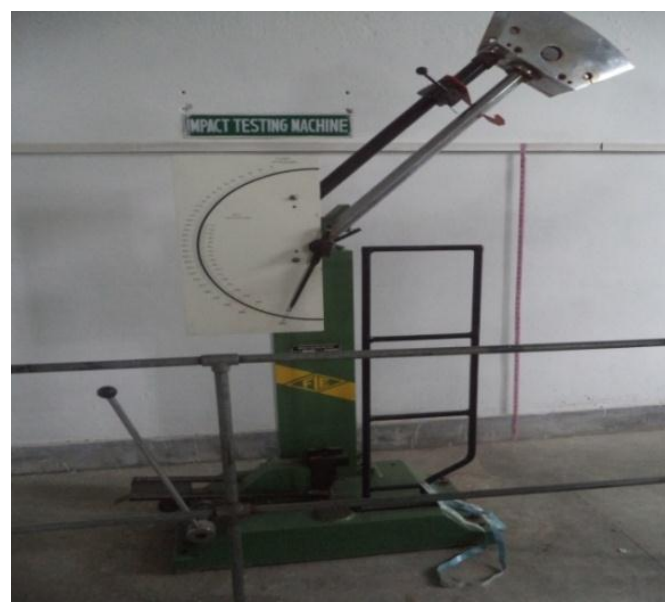

Fig: 3 Charpy Impact Testing machine

\subsection{Hardness test}

Hardness is the surface property which resists against permanent deformation in the form of scratch, cutting, indentation or mechanical wear. Hardness of each sample was measured with the help of Brinell Hardness Tester. The test employed a hardened steel ball of $2.3 \mathrm{~mm}$ dia. as indenter. The load of $150 \mathrm{kgf}$ is applied by pushing push-pull button. The effect of this load is to make indentation of depth ' $t$ ' and diameter ' $d$ '. The Brinell Hardness number (BHN) is then calculated with the help of optical microscope by measuring the diameter ' $d$ ':

$$
\mathrm{BHN}=\frac{2 \mathrm{P}}{\pi \mathrm{D}\left(\mathrm{D}-\sqrt{\left(\mathrm{D}^{2}-\mathrm{d}^{2}\right)}\right.}
$$

Where $\mathrm{P}$ is the load applied, $\mathrm{D}=$ diameter of indenter while $\mathrm{d}=$ diameter of indentation. 


\section{Experimental Results}

Experiments were carried out using L9 Standard Orthogonal Array design matrix with three levels of the process parameters. All together 9 specimens were taken to be tested with different thermal treatments. All Specimens follow the following pattern as "Annealing followed by Cryogenic Treatment \& Tempering"

It was also assumed that to test sub- zero temperature of $-196^{\circ} \mathrm{C}$ a Deep Cryogenic treatment was to be employed. The impact values were the combined effect of test parameters according to Orthogonal Array principle.

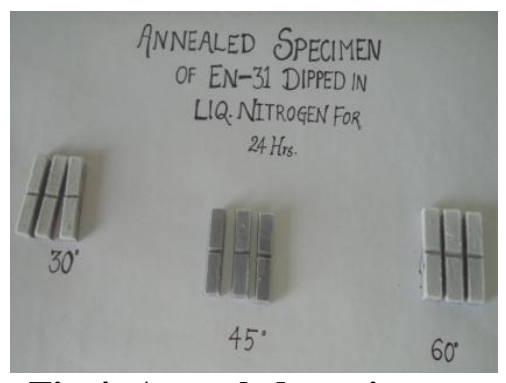

Fig 4: Annealed specimens

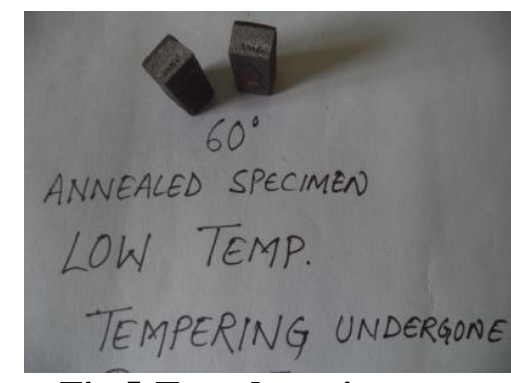

Fig 5:Tested specimen at LTT

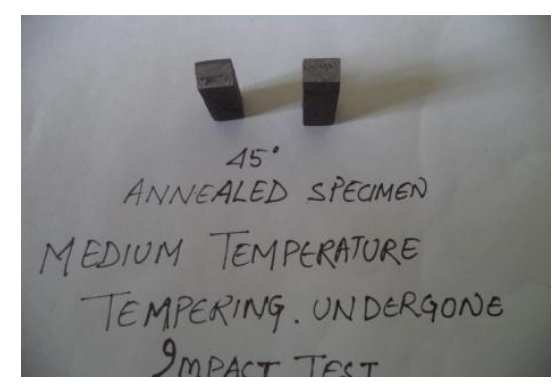

Fig 6 : Tested specimen at MTT

Table 4: Results of Experimental trials

\begin{tabular}{|c|c|c|c|c|c|c|}
\hline $\begin{array}{l}\text { Sr. } \\
\text { No. }\end{array}$ & $\begin{array}{l}\text { Notch Angle } \\
\text { (degree) }\end{array}$ & $\begin{array}{l}\text { Temperature } \\
\text { (degree Celsius) }\end{array}$ & $\begin{array}{l}\text { Height of Hammer } \\
\qquad(\mathrm{mm})\end{array}$ & Thermal Treatment & BHN & $\begin{array}{c}\text { Impact } \\
\text { Value }(J)\end{array}$ \\
\hline 1 & $30^{\circ}$ & $-196{ }^{0} \mathrm{C}$ & 1370 & ACTLTT & 95 & 75 \\
\hline 2 & $30^{\circ}$ & $-50{ }^{0} \mathrm{C}$ & 1570 & АСТМТT & 85 & 48 \\
\hline 3 & $30^{\circ}$ & $28^{0} \mathrm{C}$ & 1755 & ACTHTT & 74 & 18 \\
\hline 4 & $45^{\circ}$ & $-196{ }^{0} \mathrm{C}$ & 1570 & ACTHTT & 55 & 45 \\
\hline 5 & $45^{\circ}$ & $-50^{0} \mathrm{C}$ & 1755 & ACTLTT & 75 & 4 \\
\hline 6 & $45^{\circ}$ & $28^{0} \mathrm{C}$ & 1370 & ACTMTT & 45 & 78 \\
\hline 7 & $60^{\circ}$ & $-196{ }^{0} \mathrm{C}$ & 1755 & ACTMTT & 71 & 2.5 \\
\hline 8 & $60^{\circ}$ & $-50{ }^{0} \mathrm{C}$ & 1370 & ACTHTT & 60 & 75 \\
\hline 9 & $60^{\circ}$ & $28^{0} \mathrm{C}$ & 1570 & ACTLTT & 64 & 48 \\
\hline
\end{tabular}

\section{Results and Discussion}

All experiments have been performed on Impact Testing Machine of energy range 0-300J manufactured by Fuel instruments and Engineer Private Ltd. The response variable measured was Impact Value in Joules. Typically larger impact values are desirable. Thus the data sequences have the "larger-the-better" characteristics, the larger-the-better methodology.

Using Grey Relational Analysis the data pre-processing was obtained to normalize the random grey data with different measurement to transform them to dimensionless parameters. Thus it converts the original sequences to a set of comparable sequences

Table 5: Data Pre-Processing Result

\begin{tabular}{|ccccccccccccc}
\hline $\begin{array}{c}\text { Comparability sequence } \\
\text { (SI. No) }\end{array}$ & $\mathbf{1}$ & $\mathbf{2}$ & $\mathbf{3}$ & $\mathbf{4}$ & $\mathbf{5}$ & $\mathbf{6}$ & $\mathbf{7}$ & $\mathbf{8}$ & \\
\hline $\begin{array}{c}\text { Impact value } \\
\text { Reference sequence }\end{array}$ & $\mathbf{7 5}$ & 48 & 18 & 45 & 4 & 78 & 2.5 & 75 & 48 \\
\hline
\end{tabular}

Table 6: Deviation sequences

\begin{tabular}{|c|c|c|c|c|c|c|c|c|c|}
\hline $\begin{array}{l}\text { Comparability } \\
\text { (SI. No.) }\end{array}$ & 1 & 2 & $\overline{3}$ & 4 & 5 & 6 & 7 & 8 & 9 \\
\hline Reference sequence & 0.0397 & 0.3974 & 0.7947 & 0.4371 & 0.9801 & 0 & 1.0000 & 0.0397 & 0.3974 \\
\hline
\end{tabular}


An Experimental Study of the Effect of Thermal Treatments and Charpy Impact Test Parameters...

Table 7: Calculation of Grey Relational Co-efficient and Grey Relational Grade

\begin{tabular}{|c|c|c|c|c|c|c|}
\hline SI. No & Level 1 & Level 2 & Level 3 & G R co-efficiency & Grade & Grey order \\
\hline 1 & $30^{\circ}$ & $-196{ }^{0} \mathrm{C}$ & 1370 & 0.9264 & 0.9264 & 2 \\
\hline 2 & $30^{\circ}$ & $-50^{\circ}$ & 1570 & 0.5572 & 0.5572 & 3 \\
\hline 3 & $30^{\circ}$ & $28^{0} \mathrm{C}$ & 1755 & 0.3862 & 0.3862 & 5 \\
\hline 4 & $45^{\circ}$ & $-196{ }^{0} \mathrm{C}$ & 1570 & 0.5336 & 0.5336 & 4 \\
\hline 5 & $45^{\circ}$ & $-50{ }^{0} \mathrm{C}$ & 1755 & 0.3378 & 0.3378 & 6 \\
\hline 6 & $45^{\circ}$ & $28^{0} \mathrm{C}$ & 1370 & 1.0000 & 1.0000 & 1 \\
\hline 7 & $60^{\circ}$ & $-196{ }^{0} \mathrm{C}$ & 1755 & 0.3333 & 0.3333 & 7 \\
\hline 8 & $60^{\circ}$ & -50 & 1370 & 0.9264 & 0.9264 & 2 \\
\hline 9 & $60^{\circ}$ & $28^{0}$ & 1570 & 0.5572 & 0.5572 & 3 \\
\hline
\end{tabular}

Table 8: Response table for Grey Relational Grade

\begin{tabular}{|cccc|}
\hline & \multicolumn{2}{c}{ Factors } & Height of the Hammer \\
\hline $\mathbf{1}$ & Notch Angle & Temperature & 0.9509 \\
\hline $\mathbf{2}$ & 0.6233 & 0.5978 & 0.5493 \\
\hline $\mathbf{3}$ & 0.6238 & 0.6071 & 0.3524 \\
\hline
\end{tabular}

Average of Grey Relational Grade $=0.6176$

Table 9: Sequence after Data Pre-Processing for reference and Comparability Sequences

\begin{tabular}{|ccccc|} 
Sl. No. & \multicolumn{2}{c}{ Comparability sequence } & Reference sequence \\
\hline $\mathbf{1}$ & Notch Angle & Temperature & Height of the Hammer & 1.00 \\
\hline $\mathbf{2}$ & $30^{\circ}$ & $-196^{0} \mathrm{C}$ & 1370 & 0.64 \\
\hline $\mathbf{3}$ & $30^{\circ}$ & $-50^{\circ} \mathrm{C}$ & 1570 & 0.24 \\
\hline $\mathbf{4}$ & $30^{\circ}$ & $28^{\circ} \mathrm{C}$ & 1755 & 0.60 \\
\hline $\mathbf{5}$ & $45^{\circ}$ & $-196^{0}$ & 1570 & 0.05 \\
\hline $\mathbf{6}$ & $45^{\circ}$ & $-50^{\circ} \mathrm{C}$ & 1755 & 1.04 \\
\hline $\mathbf{7}$ & $45^{\circ}$ & $28^{\circ} \mathrm{C}$ & 1370 & 0.03 \\
\hline $\mathbf{8}$ & $60^{\circ}$ & $-196^{\circ} \mathrm{C}$ & 1755 & 1.00 \\
\hline $\mathbf{9}$ & $60^{\circ}$ & $-50^{\circ} \mathrm{C}$ & 1370 & 0.64 \\
\hline
\end{tabular}

Table 10: Response Table for Signal to Noise Ratios

\begin{tabular}{|ccccc|}
\hline Level & Notch Angle(degree) & $\begin{array}{c}\text { Temperature (Degree } \\
\text { Celsius) }\end{array}$ & $\begin{array}{c}\text { Height of the Hammer } \\
(\mathbf{m m})\end{array}$ & Thermal Treatment \\
\hline $\mathbf{1}$ & 32.08 & 26.17 & 37.61 & 31.89 \\
\hline $\mathbf{2}$ & 27.65 & 27.72 & 33.44 & 27.72 \\
\hline $\mathbf{3}$ & 26.36 & 32.19 & 15.04 & 26.48 \\
\hline Delta & 5.72 & 6.02 & 22.58 & 5.42 \\
\hline Rank & 3 & 2 & 1 & 4 \\
\hline
\end{tabular}

Table11: Response Table for Means

\begin{tabular}{|ccccc|}
\hline Level & Notch Angle (degree) & $\begin{array}{c}\text { Temperature (degree } \\
\text { Celsius) }\end{array}$ & $\begin{array}{c}\text { Height of the Hammer } \\
(\mathbf{m m})\end{array}$ & Thermal Treatment \\
\hline 1 & 47.000 & 40.833 & 76.000 & 46.000 \\
\hline 2 & 42.333 & 42.333 & 47.000 & 42.333 \\
\hline 3 & 41.833 & 48.000 & 8.167 & 42.833 \\
\hline Delta & 5.167 & 7.167 & 67.833 & 3.667 \\
\hline Rank & 3 & 2 & 1 & 4 \\
\hline
\end{tabular}




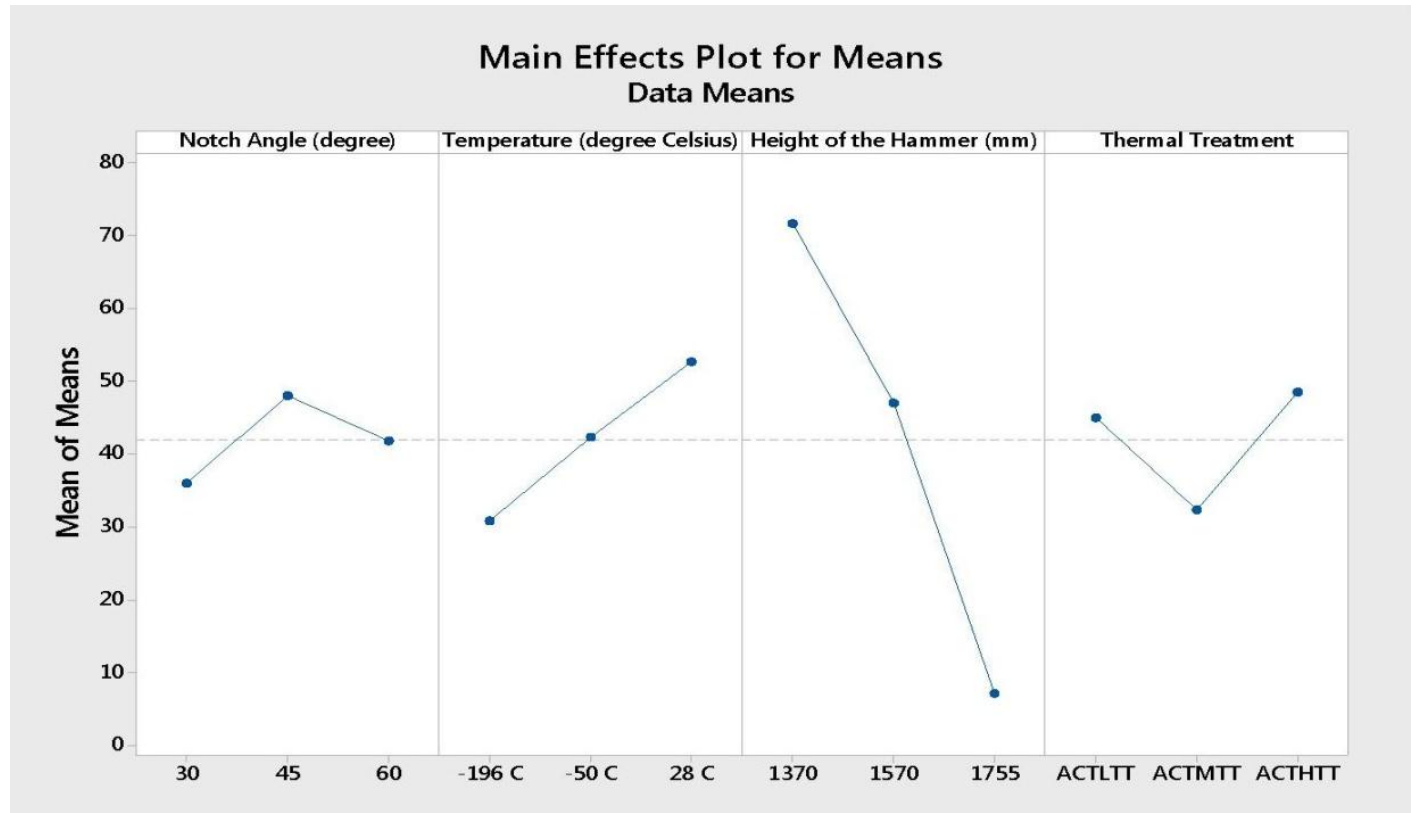

Fig 7: Main Effects plot for means

\section{Conclusion}

The present research work has successfully demonstrated the application of Taguchi based Grey relational analysis for multi objective optimization of process parameters in impact testing of EN 31 steel. The conclusions can be drawn from the present work are as follows:

1) The highest Grey relational grade of 1 was observed for the experimental run 6, shown in Table No.7 of the average Grey relational grade, which indicates that the optimal combination of control factors and their levels was $45^{\circ}$ notch angle, $28^{\circ} \mathrm{C}$ temperature, height of hammer of $1370 \mathrm{~mm}$ and thermal treatment of ACTHTT

2) The order of importance for the controllable factors was height of hammer followed by temperature, Notch angle and thermal treatment in order to get the maximum impact value.

\section{References}

[1]. Kobayashi, Hideo, Onoue, Hisahiro, Brittle Fracture of Liberty Ships, March,1943

[2]. AASHTO, Guide Specification for Fracture Critical Non-Redundant Steel Bridge Members, Washington DC , American Association of State Highway and Transportation Officials, 1978.

[3]. Website: http://www.sozogaku.com/fkd/en/cfen/CB1011020.html

[4]. S. Harisha, Bensely, D. Mohan Lal, A. Rajadurai, Gyöngyvér B. Lenkeyd, Microstructural study of cryogenically treated En 31 bearing steel, journal of materials processing technology 209,2009

[5]. V.Firouzdor, E.Nejati, F.Khomamizadeh, "Effect of Deep Cryogenic Treatment on Wear Resistance and Tool Life of M2 HSS Drill”, Journal of Materials Processing Technology 20 6, 2008, 467-472.

[6]. M. Arockia Jaswin, D. Mohan Lal. Effect of cryogenic treatment on the tensile behavior of En 52 and 21-4N valve steels at room and elevated temperatures, Materials and Design xxx (2010) xxx-xxx

[7]. A. Joseph Vimal, A. Bensely, D. Mohan lal, and K. Srinivasan, Deep cryogenicnTreatment improves wear resistance of EN 31 steel.

[8]. Raghuraman S, Thiruppathi K, Panneerselvam T, Santosh S Optimization of EDM Parameters Using Taguchi Method And Grey Relational Analysis for Mild Steel Is 2026, Nternational Journal of Innovative Research in Science, Engineering And Technology Vol. 2, Issue 7, 2013

[9]. Rahul H.Naravade, U.N.Gujar, R.R.Kharde, Optimization of Cryogenic Treatment on Wear Behaviour of D6 Tool Steel by Using DOE/RSM, International Journal of Engineering and Advanced Technology (IJEAT),ISSN: 2249 - 8958, Volume-2, Issue-2, December 2012

[10]. P.J. Ross, Taguchi techniques for quality engineering, $2^{\text {nd }}$ edition. Tata Mc Graw-Hill Publishing Company Ltd, New York, 2005. 